ominous that Mr. Mandelbaum at one point is willing without sign of qualm to throw in double or multiple shift working to facilitate the progress of the plan. Will these peasants be happier living in urban dwellings, built at a cost of $£ 175$ each, and working through the night in a mill ? The old economics insisted on freedom of choice in theory, although in many cases it was admittedly unreal in practice. It is a weakness, however, to give up the theory.

$\mathrm{Mr}$. Steindl's monograph is nearer to reality and is of great immediate interest. Using American statistical data as a basis for generalizations regarding the relations of size, cost, efficiency and profit in business, he analyses the implications and mutual consistency of the generalizations with great skill. The trend of the argument is in favour of large size; on the other hand, when a certain size is reached, monopolistic or oligopolistic features in the situation may tend to retard progress. "There are sufficient grounds to believe that the cause of technical progress in the present stage of development is not well served by either big or small business. There seems to be something wrong with both of them."

Mr. Steindl has a fine mastery of analysis, and his book is an outstanding contribution. There is a small slip on pp. 37-38. He is right in holding that if we accept Keynes' theories there is no need in the existing situation to reckon interest on capital in, when measuring relative efficiencies; but he is wrong in implying, as he appears to, that we need not reckon in the amortization of capital either. The resources required for increasing capital intensity could always be spent on current consumption; their absorption is a genuine cost.

It must be recorded that in this volume, too, the human factor is neglected, less obviously but this time without any safeguarding disclaimer. Searching about for a reason why small entrepreneurs accept unusually high risks at low remuneration rather than become employees, Mr. Steindl lights upon the explanation that it is to maintain "a higher social status". It would be difficult to find a more striking example of complete disregard of the passions and values that animate ordinary people outside the study. Again, when persons prefer to deal with old customers, this is due to "force of habit, ignorance or laziness". This is the economic steam-roller with a vengeance! Luckily economic wants are not so pressing in the United States (from which the data for this. study are derived) that people must needs sacrifice the more precious things of life in order to add somewhat to material income. Even the poor British may have some little room for non-economic aims.

\section{TEXT-BOOK OF OPTICS}

\section{Optique Instrumentale}

Par Prof. G.-A. Boutrost Pp. $x+540$. Masson et Cie., 199 link.p. 7 HE strpgth and spirit of the contemporary this adm able book, which carries its subject through maphan five hundred pages without allowing the interest to flag. As the author explains in a preface, the treatment is based on his course of lectures in instrumental optics, given at the École supérieure d'Optique. Side by side with this course, the students receive another on optical computation, which subject is therefore omitted from the present treatise. For a similar reason, namely, the existence of Danjon and Couder's "Lunettes et télescopes", astronomical optics is only briefly dealt with. What is left, that is to say the main body of the ssubject, is set out with skill and enthusiasm in twenty-two chapters, of which the last six are separate monographs.

Perhaps the most valuable of these monographs is the one which treats of the visual microscope. Objective, illuminating system and mounting are given equality of status in the discussion, which is refreshingly practical in outlook. An account of the phase-contrast method is included, but this is below the standard of the rest of the chapter; Zernike's name is consistently misspelt in the text, and the captions of Fig. $340(b)$ and $(c)$ are misleading. These two photographs actually illustrate the appearances with a 'positive' (that is, phase-advancing) annular. strip and a 'negative' straight strip, and were used by Zernike in support of his view that for most purposes the annular form of strip is preferable.

In the first seven chapters of the book, the basic theory of centred systems is developed, always with an $\theta y e$ to practical application, from its beginnings through Snell's law (Descartes' law), focal lines and caustics, the Herschel and Abbe conditions, Airy's condition and the properties of spherical aberration and coma. Mathematical demands on the reader are kept down to the minimum throughout and no systematic account of the Seidel theory is attempted. Considerable space is devoted, on the other hand, to the details of Gaussian theory and its application to thick lenses. Chapters 8 and 9 set out the principles underlying the practical designing of achromatic doublets and of eyepieces.

The next three chapters deal with prism-trains and with cylindrical systems. An incorrect theorem on p. 217 (to which M. Boutry has directed the attention of reviewers) fortunately has no serious consequences later.

Chapters 13 and 14 are devoted to the human eye and the amelioration of its defects; a welcome feature is the short but valuable section on visual acuity. Chapter 15 is of a more miscellaneous character; under the title "geometrical properties of visual instruments" are discussed such questions as field-size, depth of field, perspective and relief, and imagebrilliance in different parts of the field.

The main part of the book concludes with a chapter on resolving power. In its lucidity of exposition, and in the ground it succeeds in covering with the help of very little mathematical formalism, this chapter is one of the most striking in the book. Especially helpful is the way in which the author himself raises and tries to meet the honest doubts which are likely to assail a thoughtful student confronted for the first time with the Huyghens-Fresnel theory.

The attitude to the subject which vitalizes the whole book is expressed in a few pregnant sentences in the preface, which are worth quoting here. After pointing out that students must contrive to assimilate in succession the two very different outlooks of geo. metrical and of instrumental optics, M. Boutry goes on : "Leur préparation est complète dès que, rompus et assouplis, l'expérience et l'expérience seule aura pu leur enseigner la manière dont on doit, en pratique, fondre les deux dogmes. Aucun autre professeur ne peut terminer leur formation : c'est confesser peut-être que l'Optique instrumentale reste un art; cela ne diminue point les hommes qui la créent chaque jour.";
E. H. LINTOOT 